\title{
Could pulmonary low-dose radiation therapy be an alternative treatment for patients with COVID-19 pneumonia? Preliminary results of a multicenter SEOR-GICOR nonrandomized prospective trial (IPACOVID trial)
}

\author{
M. Arenas ${ }^{1,2,3} \cdot$ M. Algara ${ }^{4,5,6}$ (D) - G. De Febrer ${ }^{1,7} \cdot$ C. Rubio ${ }^{8} \cdot$ X. Sanz R,6,9 $^{4}$ M. A. de la Casa ${ }^{8}$ et al. [full author details \\ at the end of the article]
}

Received: 1 March 2021 / Accepted: 1 June 2021 / Published online: 6 July 2021

(c) The Author(s) 2021, corrected publication 2021

\begin{abstract}
Purpose To evaluate the efficacy and safety of lung low-dose radiation therapy (LD-RT) for pneumonia in patients with coronavirus disease 2019 (COVID-19).

Materials and methods Inclusion criteria comprised patients with COVID-19-related moderate-severe pneumonia warranting hospitalization with supplemental $\mathrm{O}_{2}$ and not candidates for admission to the intensive care unit because of comorbidities or general status. All patients received single lung dose of $0.5 \mathrm{~Gy}$. Respiratory and systemic inflammatory parameters were evaluated before irradiation, at $24 \mathrm{~h}$ and 1 week after LD-RT. Primary endpoint was increased in the ratio of arterial oxygen partial pressure $\left(\mathrm{PaO}_{2}\right)$ or the pulse oximetry saturation $\left(\mathrm{SpO}_{2}\right)$ to fractional inspired oxygen $\left.(\mathrm{FiO})_{2}\right)$ ratio of at least $20 \%$ at $24 \mathrm{~h}$ with respect to the preirradiation value.

Results Between June and November 2020, 36 patients with COVID-19 pneumonia and a mean age of 84 years were enrolled. Seventeen were women and 19 were men and all of them had comorbidities. All patients had bilateral pulmonary infiltrates on chest X-ray. All patients received dexamethasone treatment. Mean $\mathrm{SpO}_{2}$ pretreatment value was $94.28 \%$ and the $\mathrm{SpO}_{2} / \mathrm{FiO}_{2}$ ratio varied from $255 \mathrm{~mm} \mathrm{Hg}$ to $283 \mathrm{~mm} \mathrm{Hg}$ at $24 \mathrm{~h}$ and to $381 \mathrm{~mm} \mathrm{Hg}$ at 1 week, respectively. In those who survived (23/36, 64\%), a significant improvement was observed in the percentage of lung involvement in the CT scan at 1 week after LD-RT. No adverse effects related to radiation treatment have been reported.

Conclusions LD-RT appears to be a feasible and safe option in a population with COVID-19 bilateral interstitial pneumonia in the presence of significant comorbidities.
\end{abstract}

Keywords COVID-19 pneumonia $\cdot$ Low-dose radiation therapy $\cdot$ Treatment outcome $\cdot$ Anti-inflammatory effects $\cdot$ Lung irradiation

\section{Introduction}

Since the beginning of 2020 when coronavirus disease 2019 (COVID-19) appeared, the world has been battling against a new and practically unknown highly contagious viral infection which yet has no cure. Although the majority of infected people develop only mild, if not practically asymptomatic, clinical effects, most serious clinical manifestations of the severe acute respiratory syndrome (SARS)-

M. Algara, MD, PhD

malgara@parcdesalutmar.cat

Extended author information available on the last page of the article
CoV-2 virus infection derive mainly from the hyperinflammatory lung response that some infected patients experience, which leads to SARS, the cause of death from COVID-19 in many cases [1].

Numerous pharmacological alternatives have been proposed although none have proven to be definitively effective. In this context, a number of groups in different parts of the world have been exploring the idea of a one-off effective radiotherapy treatments in lung pneumonia. Several publications have proposed theoretical bases for the usefulness of radiotherapy in COVID-19 and although the idea of using radiation therapy to treat different respiratory disorders is not new [2-4], it has generally been met with prejudice and fear that often accompany the therapeutic use of ionizing radiation. Advances in radiobiology help 
us to understand the efficacy of low-dose radiation therapy (LD-RT) as a plausible anti-inflammatory treatment. Radiotherapy doses conventionally used in the treatment of neoplastic diseases induce the production and release of proinflammatory cytokines. However, low doses of between 0.3-0.7 Gy induce a totally opposite phenotype thanks to their effect on leukocytes, macrophages, polymorphonuclear cells, and vascular endothelial cells. LD-RT provokes a decrease in pro-inflammatory mediators, such as reactive oxygen species (ROS), nitric oxide synthetase (iNOS), tumor necrosis factor (TNF)- $\alpha$, selectin L- and E-, or interleukin (IL)-beta 1. Additionally, LD-RT favors a change in macrophage polarization from a pro-inflammatory $\mathrm{M}-1$ phenotype to an anti-inflammatory M-2 phenotype at the same time as increasing the secretion of anti-inflammatory mediator transforming anti-inflammatory cytokine growth factor $\beta 1$ (TGF- $\beta 1$ ) and apoptosis mediators nuclear factor kappa-beta (NF-KB) [5-9]. Based on this knowledge, several studies of pulmonary LD-RT in COVID-19 pneumonia have been initiated in different countries [10].

We hypothesized that pulmonary LD-RT can prevent or reduce the lung inflammatory cascade produced by COVID19 and it can be an alternative treatment for these patients. We report here the results of a whole lung LD-RT multicenter trial on 36 patients with COVID-19-related pneumonia.

\section{Materials and methods}

The protocol details of this multicenter, nonrandomized prospective trial have been published previously [11]. The main study objective was to evaluate the efficacy of single pulmonary LD-RT $(0.5 \mathrm{~Gy})$, evaluated according to an increase in arterial oxygen partial pressure $\left(\mathrm{PaO}_{2}\right)$ to fractional inspired oxygen $\left(\mathrm{FiO}_{2}\right)\left(\mathrm{PaO}_{2} / \mathrm{FiO}_{2}\right)$ ratio or the pulse oximetry saturation $\left(\mathrm{SpO}_{2}\right)$ to $\mathrm{FiO}_{2}\left(\mathrm{SpO}_{2} / \mathrm{FiO}_{2}\right)$ ratio of at least $20 \%$ at $24 \mathrm{~h}$ with respect to the pre-irradiation value in at least $30 \%$ of the treated and evaluable patients. Secondary objectives included positive changes in radiological image, mortality at 15 and 30 days after LD-RT, and the effects on inflammatory blood parameters including the determination of C-reactive protein (CRP), interleukin-6 (IL6), ferritin, D-dimer (DD) and lactic acid dehydrogenase $(\mathrm{LDH})$. We consider necessary to note that although this trial was designed in 2 phases: a first exploratory phase that intended to recruit 10 patients to evaluate the viability and efficacy of single-fraction pulmonary RT-LD, and a second, nonrandomized comparative phase with a control group, its interest during the COVID-19 pandemic triggered recruitment from the initial phase to the 36 patients we now report.

Inclusion criteria comprised patients with COVID-19-related moderate-severe pneumonia who were not candidates for admission to the intensive care unit (ICU) because of comorbidities or low performance status. The LD-RT plan comprised a single dose of $0.5 \mathrm{~Gy}$, although the protocol included the possibility of administering a second dose of $0.5 \mathrm{~Gy}$ after $48 \mathrm{~h}$, depending on the response to the first and individualizing every case. A planning computed tomography (CT) scan with axial images obtained at $3 \mathrm{~mm}$ intervals throughout the lung was acquired from all patients who were candidates for LD-RT. Clinical target volume (CTV) included both lungs. The radiotherapy plan consisted of anterior posterior-posterior anterior 2-field conformal treatment for both lungs without any type of protection (Supplementary information Figure A1). Due to the ultra-low prescribed, defining dose, specific constraints were not considered necessary for healthy organs beyond the ALARA (as low as reasonably achievable) principle.

To evaluate the efficacy of the treatment, variations in the daily oxygen supply needs according to the $\mathrm{FiO}_{2}$, which represents the percentage of oxygen participating in gas exchange, and periodic determinations of $\mathrm{PaO}_{2} / \mathrm{FiO}_{2}$ or $\mathrm{SpO}_{2} / \mathrm{FiO}_{2}$ ratio, radiologic evaluation of lung infiltrates and determination of inflammation markers were carried out and measured before irradiation (basal) and at $24 \mathrm{~h}$ and at 1 week after treatment. In some cases (13/36), it was also possible to analyze all parameters at 1 month after LD-RT.

To assess the functional status and potential risk of the study population, we decided to use two existing tools designed for this purpose. The Barthel Index was used to evaluate patients' functional independence by means of an ordinal scale used to measure performance in activities of daily living (ADL), and the CURB-65 Severity Score is a clinical prediction rule that has been validated for estimating mortality of community-acquired pneumonia measuring Confusion, blood Urea nitrogen (BUN), Respiratory rate, Blood pressure and age over 65. Due to the cognitive impairment and several comorbidities that all elderly patients presented in this trial, we classified the groups into three different subgroups: survivors (group A), deaths from COVID19 (group B) and deaths from other causes (group C), in order to support the initial supposition of severe cognitive impairment and associated increased risk of death.

All statistical analysis and graph representations were performed by SPSS software (SPSS 22.0, Chicago, IL, USA), 'R' software version 4.0.2 (https://www.r-project. org/) and GraphPad Prism 6.01 (GraphPad Software, San Diego, CA, USA). To assess the distribution of the variables was used the Kolmogorov-Smirnov test. Through the Mann-Whitney $U$-test (nonparametric) we evaluated differences between any two groups of variables and for comparisons of dependent variables we used the Wilcoxon signedrank test. To assess differences between qualitative variables we employed the $\chi^{2}$ test. Medians and interquartile 
Table 1 Clinical characteristics of patients with COVID-19 treated with low-dose radiation therapy

\begin{tabular}{|c|c|}
\hline Variables & $(n=36)$ \\
\hline$\overline{\text { Age }}$ & $83.64(8.11)^{b}$ \\
\hline \multicolumn{2}{|l|}{ Sex } \\
\hline Female & $17(47.2)^{\mathrm{a}}$ \\
\hline Male & $19(52.8)$ \\
\hline Neurologic diseases & $10(27.8)^{b}$ \\
\hline Cardiovascular diseases & $30(83.3)^{b}$ \\
\hline Respiratory diseases & $12(33.3)^{b}$ \\
\hline Other comorbidities & $31(86.1)^{\mathrm{b}}$ \\
\hline Days with symptoms & $5.72(1.54)^{\mathrm{b}}$ \\
\hline \multicolumn{2}{|l|}{ Functional status (Barthel Index) } \\
\hline Independent & $6(16.7)^{\mathrm{a}}$ \\
\hline Minimally dependent & $12(33.3)$ \\
\hline Partially dependent & $7(19.4)$ \\
\hline Very dependent & $8(22.2)$ \\
\hline Total dependent & $3(8.3)$ \\
\hline \multicolumn{2}{|l|}{ Geriatric Depression Scale (GDS) } \\
\hline No cognitive decline & $18(50)^{\mathrm{a}}$ \\
\hline Very mild cognitive decline & $8(22.2)$ \\
\hline Mild cognitive decline & $5(13.9)$ \\
\hline Moderate cognitive decline & - \\
\hline Moderately severe cognitive decline & $2(5.6)$ \\
\hline Severe cognitive decline & $3(8.3)$ \\
\hline Very severe cognitive decline & - \\
\hline \multicolumn{2}{|l|}{ Pharmacological treatment } \\
\hline Corticosteroids (dexamethasone) & $36(100)^{\mathrm{a}}$ \\
\hline Remdesivir & $2(5.6)$ \\
\hline Tocelizumab & $2(5.6)$ \\
\hline Basal $\mathrm{SpO}_{2}$ & $94.28(2.85)^{\mathrm{b}}$ \\
\hline Basal SaFi & $255.42(117.75)^{\mathrm{b}}$ \\
\hline Mild & $18(50)^{\mathrm{a}}$ \\
\hline Moderate & $5(13.9)$ \\
\hline Severe & $13(36.1)$ \\
\hline Basal PaFi & $251.39(128.19)^{b}$ \\
\hline Mild & $25(69.4)^{\mathrm{a}}$ \\
\hline Moderate & $4(11.1)$ \\
\hline Severe & $7(19.4)$ \\
\hline \multicolumn{2}{|l|}{ CURB-65 Score } \\
\hline 1 points & - \\
\hline 2 points & $10(27.8)^{\mathrm{a}}$ \\
\hline 3 points & $17(47.2)$ \\
\hline 4 points & $9(25)$ \\
\hline \multicolumn{2}{|l|}{ CT lung involvement (\%) } \\
\hline$<5 \%$ & - \\
\hline $5-25 \%$ & $1(2.8)^{\mathrm{a}}$ \\
\hline $26-50 \%$ & $7(19.4)$ \\
\hline $51-75 \%$ & $18(50)$ \\
\hline$>75 \%$ & $10(27.8)$ \\
\hline
\end{tabular}

Table 1 (Continued)

\begin{tabular}{ll}
\hline Variables & $(\boldsymbol{n = 3 6 )}$ \\
\hline Final status & $23(63.9)^{\mathrm{a}}$ \\
Alive & $8(22.2)$ \\
Death due to COVID-19 & $5(13.9)$ \\
Death due to other causes & \\
\hline
\end{tabular}

CT Computed Tomography; CURB-65 validated clinical prediction score for predicting mortality in community-acquired pneumonia and infection of any site including measurement of: Confusion of new onset, Blood Urea Nitrogen, Respiratory rate, Blood pressure and Age; $\mathrm{PaFi}$ ratio of arterial oxygen partial pressure $\left(\mathrm{PaO}_{2}\right)$ to Fractional Inspired Oxygen $\left(\mathrm{FiO}_{2}\right) ; \mathrm{SpO}_{2}$ oxygen saturation; $\mathrm{SaFi}$ ratio of $\mathrm{SpO}_{2}$ to $\mathrm{FiO}_{2}$

${ }^{a}$ Results shown as frequencies and percentages in parenthesis

${ }^{b}$ Results shown as means and standard deviations in parenthesis

ranges were expressed for quantitative variables and frequencies and percentages for qualitative variables. We considered significant differences when the $p$-value was $<0.05$.

This protocol conforms to international regulations and is in accordance with the recommendations established in the Declaration of Helsinki. The study was approved by the Institution Research Board of each center and is registered in ClinicalTrials.gov (NCT NCT04380818).

\section{Results}

Between June and November 2020, 36 patients with COVID-19 pneumonia participated in this trial. All of them signed the consent form before treatment. Table 1 gives the patients' baseline characteristics. In all, 19 men and 17 women were included, with a mean age of 84 years, all of them presenting multiple comorbidities, the most common being cardiovascular disease. Patients were classified according to the Barthel Index as 'independent' in 6 cases (16.7\%), 'mild dependence' in $12(33.3 \%)$, 'moderate dependence' in 7 (19.4\%), 'severe dependence' in 8 (22.2\%) and 'completely dependent' in 3 (8.3\%). All patients had bilateral pulmonary infiltrates on chest X-ray at diagnosis. The radiological pneumonia, measured according to percentage of lung parenchyma affected on pretreatment CT, showed that $27.8 \%$ presented affection of $>75 \%, 50 \%$ of $51-75 \%, 19.4 \%$ of $26-50 \%$ and $2.8 \%$ only $5-25 \%$. A mean pre-irradiation $\mathrm{SpO}_{2}$ of $94.28 \%$. Mean value of CRP was $9 \mathrm{mg} / \mathrm{dL}(1.14-24.7 \mathrm{mg} / \mathrm{dL})$. All patients received dexamethasone treatment, one patient also received tocilizumab, one received remdesivir, and a third patient received both of them. All patients received a dose of $0.5 \mathrm{~Gy}$ and although considered in trial protocol, a second $0.5 \mathrm{~Gy}$ dose was not administered in any patient. During the follow-up month, no patients presented radiation-related adverse effects.

The evaluation of respiratory parameters at $24 \mathrm{~h}$ was possible for 34/36 patients (94.4\%). $\mathrm{SpO}_{2} / \mathrm{FiO}_{2}$ and $\mathrm{PaO}_{2} / \mathrm{FiO}_{2}$ 
Fig. 1 Evolution of respiratory parameters $\left(\mathrm{SpO}_{2} / \mathrm{FiO}_{2}[\mathbf{a}]\right.$ and $\left.\mathrm{PaO}_{2} / \mathrm{FiO}_{2}[\mathbf{b}]\right)$ in all patients with COVID-19 treated with low-dose radiation therapy classified by survivors, COVID-19 deaths and deaths from other causes
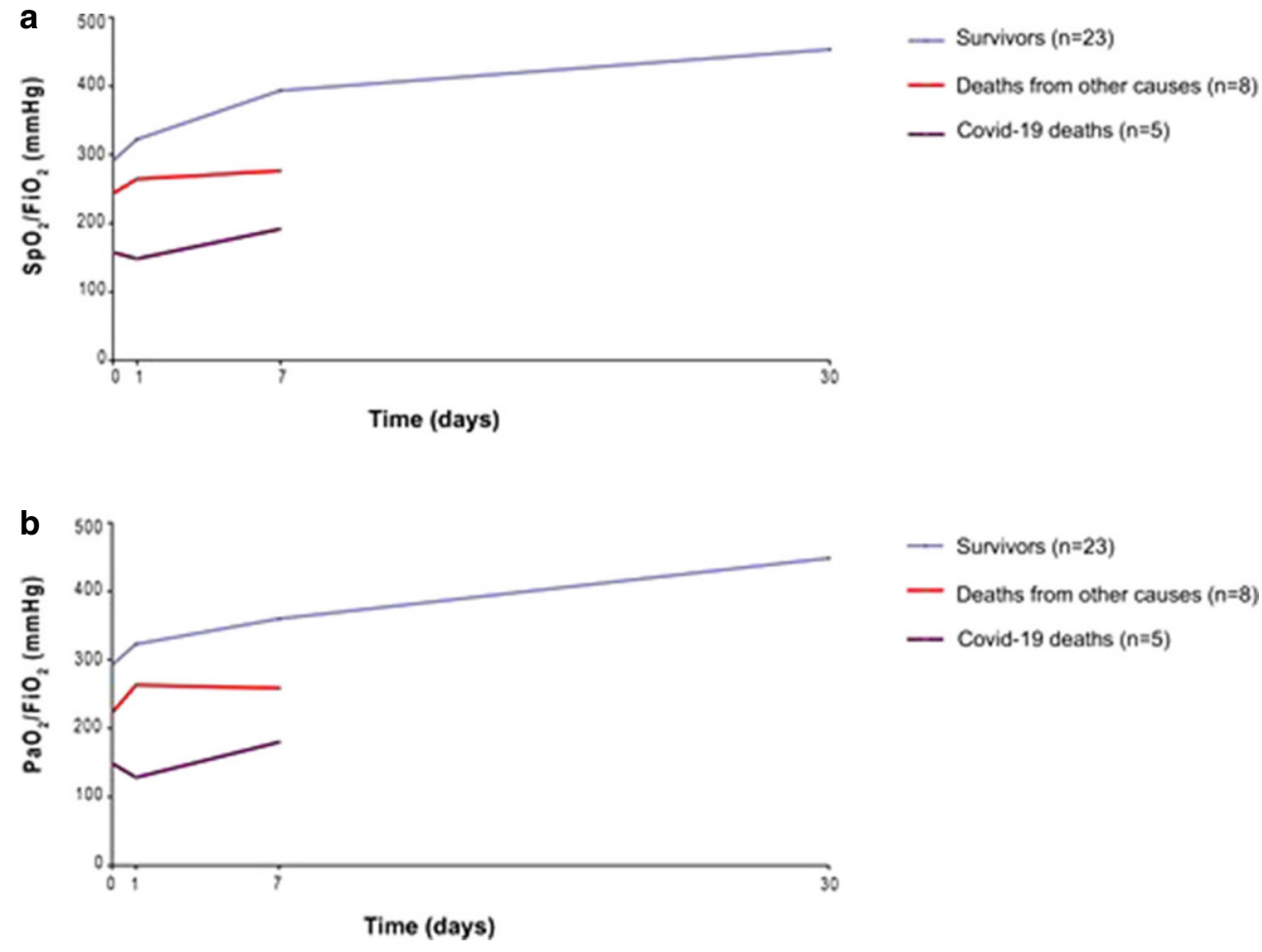

values were significantly higher $(p<0.01)$ in survivors than COVID-19 deaths only at baseline and 24h after LD-RT. Seventeen patients $(50 \%)$ presented an improvement of $\mathrm{SpO}_{2} / \mathrm{FiO}_{2}$, with a mean percentage of $38.82 \%$ compared to baseline value. At 1 week, 25/36 were evaluable and of them, 21 patients (84\%) presented a mean $\mathrm{SpO}_{2} / \mathrm{FiO}_{2}$ improvement of $76 \%$, while the other 4 patients did not present any improvement. We were able to examine the first 13 patients after 1 month of LD-RT at the time of the statistical evaluation, observing that none of them needed any supplemental oxygen therapy, and $\mathrm{SpO}_{2} / \mathrm{FiO}_{2}$ ratio was higher in all of them, increasing its value with a mean of $77.98 \%$ (463 mm Hg) (Fig. 1). Fig. 2 shows all respiratory parameters (2A) and inflammatory biochemical results (2B) before and at $24 \mathrm{~h}$ after LD-RT in all three groups. In groups $\mathrm{A}$ and $\mathrm{C}$, there was an improvement in the respiratory parameters $\left(\mathrm{SpO}_{2} / \mathrm{FiO}_{2}, \mathrm{PaO}_{2} / \mathrm{FiO}_{2}\right.$ and $\left.\mathrm{FiO}_{2}\right)$. In all groups a decrease in CRP was observed. Supplementary Information Figure A2 shows a significant improvement in the respiratory parameters and biochemical results before and after LD-RT. Table 2 shows biochemical variables of patients with COVID-19, classified by survivors, COVID19 deaths and deaths from other causes, before, at $24 \mathrm{~h}$, 1 week, and 1 month after LD-RT.

Causes of patients' death are shown in Table 3. Seven patients (19.4\%) died from COVID-19 in the first week and 1 patient died on day 11 following LD-RT. All of them presented a high CURB-65 value, 3 and 4 points, and bilateral pneumonia with $>50 \%$ lung affection on CT. Additionally, 5 patients $(13.8 \%)$ died from other causes during the followup. Supplementary Information Table A1 shows the evaluation of CURB-65 in survivors, COVID-19 deaths and deaths from other causes evaluated before LD-RT, at $24 \mathrm{~h}$, at 1 week and at 1 month after LD-RT. Those patients who died of COVID-19 pneumonia had a significantly worse CURB-65 score before and at $24 \mathrm{~h}$ after LD-RT, confirming that high-risk pneumonia is a predictor of death $(p<0.01)$. Supplementary Information Figure A3 shows an improvement in the evolution of the radiological manifestations of COVID-19 pneumonia in one patient. No statistically significant differences were found in the 3 subgroups according to the Barthel Index, probably because of the small sample size in some subgroups, although there seems to be a trend towards a greater degree of dependence in group B (Supplementary Information Table A2).

\section{Discussion}

When SARS-CoV-2 infects the lungs of a previously healthy patient by binding to the membrane receptor for angiotensin converting enzyme-2 (ACE2), it stimulates a series of intracellular pathways favoring the release of pro-inflammatory cytokines and the recruitment of immune cells resulting in the induction of a hyperinflammatory state. That appears to be the key triggering mechanism 
Fig. 2 Selected respiratory (a) and biochemical (b) parameters comparisons between survivors, COVID-19 deaths and deaths from other causes before treatment and at $24 \mathrm{~h}$ after received treatment with low-dose radiation therapy (RT)
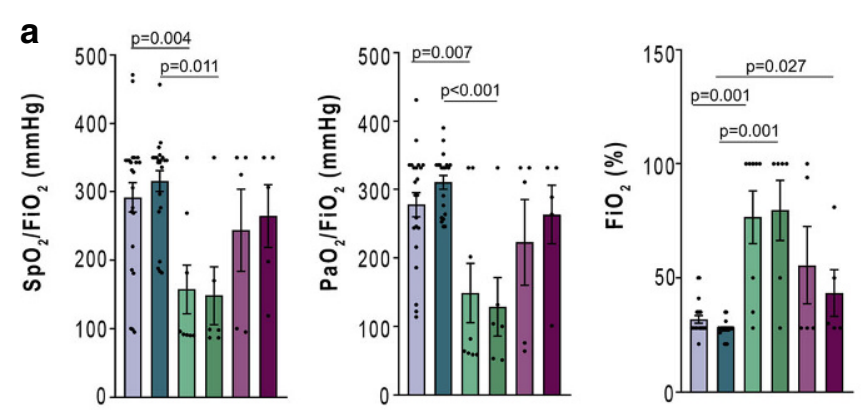

Survivors before RT

- Survivors after RT

Covid-19 deaths before RT

Covid-19 deaths after RT

Deaths from other causes before RT

Deaths from other causes after RT
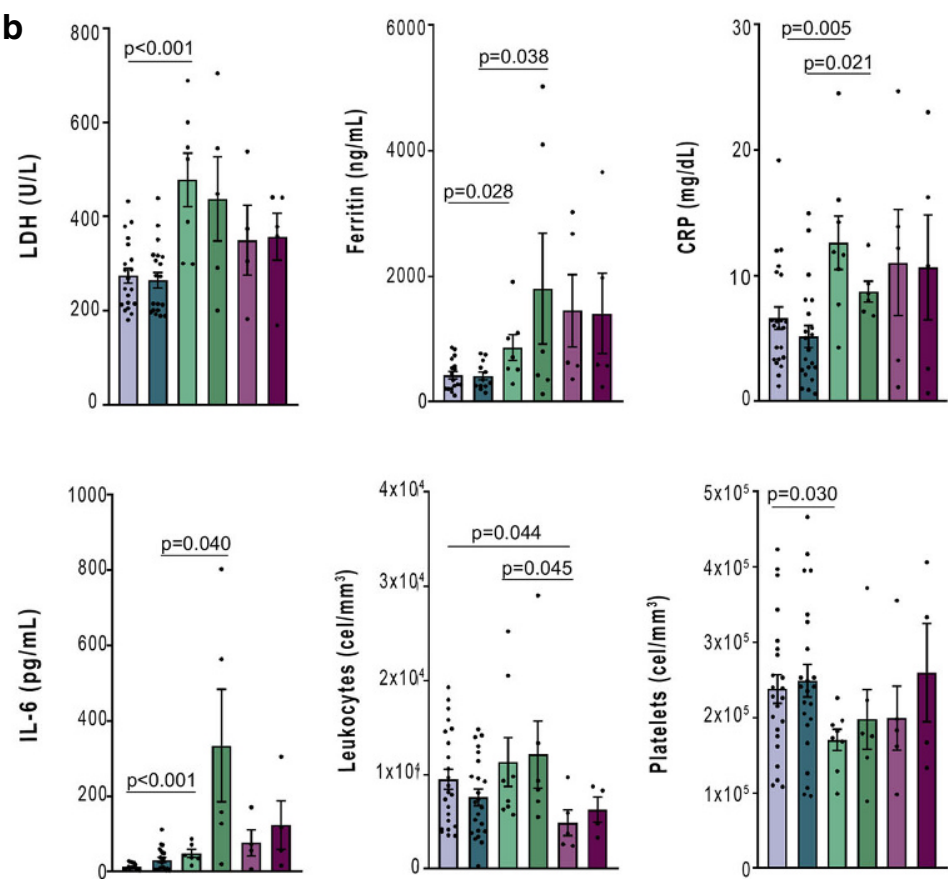

for the most severe forms of infection [12]. To date, the only measures that have shown any degree of efficacy are those aimed at combating the process of inflammation and pulmonary SARS [13]. The treatments specifically directed against the overexpression of known mediators of inflammation such as IL- 1 or IL- 6 are among the few measures that have shown certain efficacy $[14,15]$. The RECOVERY Collaborative Group randomized phase III study showed that the use of dexamethasone reduced death among those who were receiving either invasive mechanical ventilation or oxygen alone and reinforced the usefulness of corticosteroids for COVID-19 patients [16]. In the double-blind, randomized Adaptive COVID-19 Treatment Trial (ACTT1), the antiviral agent remdesivir has been shown to be more effective than a placebo in hastening the recovery of hospitalized patients with COVID-19 pneumonia [17]. Dexamethasone and remdesivir are the only treatments that have shown true efficacy against COVID-19 [18]. Other 


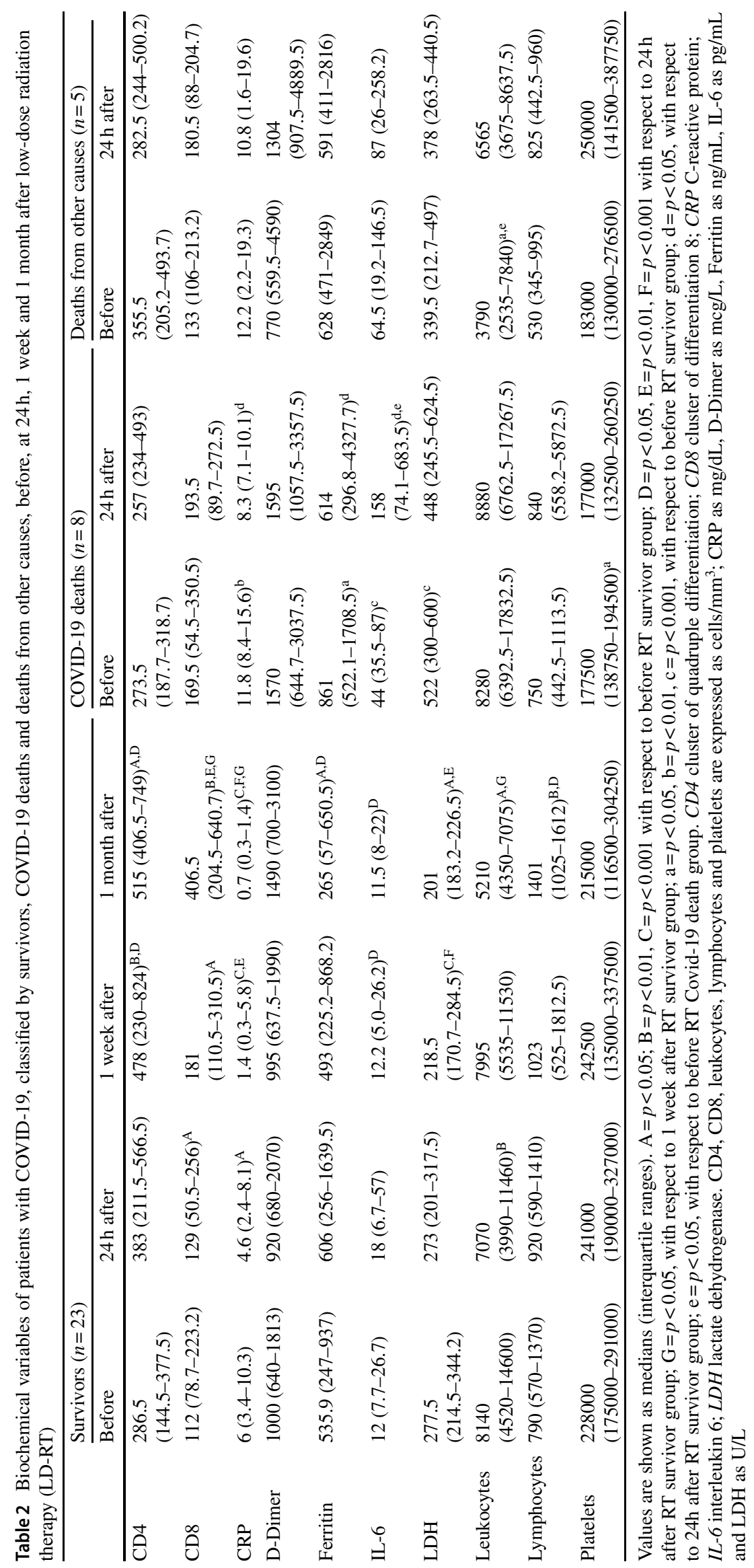


Table 3 Causes of death, from COVID-19 or other causes following low-dose radiation therapy (LD-RT)

\begin{tabular}{|c|c|c|c|c|}
\hline Patient & $\begin{array}{l}\text { Death day after } \\
\text { LD-RT }\end{array}$ & COVID-19 & Age & Reason \\
\hline 1 & $1^{\text {st }}$ & Yes & 91 & $\begin{array}{l}\text { Severe cognitive impairment and constantly removed the ventilation mask her- } \\
\text { self }\end{array}$ \\
\hline 2 & $2^{\text {nd }}$ & Yes & 86 & Acute respiratory distress secondary to COVID-19 (SaFi had worsened by $3 \%$ ) \\
\hline 3 & $3^{\text {rd }}$ & Yes & 72 & $\begin{array}{l}\text { Severe cognitive impairment and constantly removed the ventilation mask her- } \\
\text { self }\end{array}$ \\
\hline 4 & $3^{\text {rd }}$ & Yes & 86 & Acute respiratory distress secondary to COVID-19 (SaFi had improved a 3\%) \\
\hline 5 & $4^{\text {th }}$ & Yes & 89 & $\begin{array}{l}\text { Severe cognitive impairment and constantly removed the ventilation mask her- } \\
\text { self }\end{array}$ \\
\hline 6 & $6^{\text {th }}$ & Yes & 88 & Acute respiratory distress secondary to COVID-19 \\
\hline 7 & $7^{\text {th }}$ & Yes & 88 & Acute respiratory distress secondary to COVID-19 (SaFi had improved by $7 \%$ ) \\
\hline 8 & $7^{\text {th }}$ & No & 74 & $\begin{array}{l}\text { Septic infection of unknown origin without response to empiric antibiotic ad- } \\
\text { ministration }\end{array}$ \\
\hline 9 & $8^{\text {th }}$ & No & 73 & $\begin{array}{l}\text { Bronchoaspiration, having a subdural hemorrhage recent intervention. SaFi was } \\
\text { stable without changes since basal determination }(350 \mathrm{~mm} \mathrm{Hg})\end{array}$ \\
\hline 10 & $11^{\text {th }}$ & Yes & 87 & $\begin{array}{l}\text { Acute respiratory distress secondary to COVID-19 (SaFi had worsened by } 45 \% \\
\text { in } 7 \text { days) }\end{array}$ \\
\hline 11 & $12^{\text {th }}$ & No & 60 & Severe worsening of his chronic renal failure under hemodialysis treatment \\
\hline 12 & $14^{\text {th }}$ & No & 55 & $\begin{array}{l}\text { Esophageal varices hemorrhage, having a known antecedent of enolic hepatic } \\
\text { disease (he had improved SaFi from basal } 95 \mathrm{~mm} \mathrm{Hg} \text { to } 277 \mathrm{~mm} \mathrm{Hg} \text { in one } \\
\text { week) }\end{array}$ \\
\hline 13 & $25^{\text {th }}$ & No & 85 & Severe pulmonary thromboembolism \\
\hline
\end{tabular}

strategies, such as the use of plasma from recovered convalescent patients might reduce the risk of death and could be an attractive strategy if subsequent studies confirm its efficacy [19].

Due to the lack of a definitive treatment and in accordance with the previously mentioned theoretical and experimental bases, the efficacy of LD-RT has been hypothesized for the treatment of respiratory complications associated with COVID-19 and numerous studies have been initiated by various groups [10]. The idea of using LD-RT to the lungs to treat pneumonia is not new. The review by Calabrese et al. collected evidence of 863 cases of pneumonia treated with LD-RT between 1905 and 1946 [4]. Observed results suggested the efficacy of LD-RT, although it must be kept in mind that these are old studies of retrospective nature, methodologically debatable according to present standards, using various treatment techniques considered obsolete today and many of them lacking a control group. Although when it was published it showed consistent data with the normal evolution of pneumonia at that time, it would be advisable to handle those results with caution. The mechanism of LD-RT, such as those proposed for the treatment of COVID-19 pneumonia, has different actions, including the reduction of pro-inflammatory cytokines while inhibiting the interaction between polymorphonuclear leukocytes and the vascular endothelium, and favors the polarization of lung macrophages from a pro-inflammatory M-1 phenotype to an anti-inflammatory M-2 phenotype [20, 21]. These changes, which favor the establishment of a local anti-inflammatory environment, would explain the clinical effects of LD-RT. Studies of pulmonary LD-RT currently underway are focusing on patients with presence of confirmed COVID-19 disease and radiologically evident pneumonia. Most trials have administered a single fraction of $0.5-1.5$ Gy to both lungs, although three studies have considered administering a second identical fraction if there is no adequate response after the first during a time interval that varies between 24 and $240 \mathrm{~h}$ after the first fraction. The main objective of many of them is an improvement in oxygen saturation rates, although some studies also evaluated other aspects, such as the length of hospital stay, the need for admission to ICU, an improvement in radiology or the associated crude mortality rates [22]. In our trial, the primary endpoint of improving the $\mathrm{PaO}_{2} / \mathrm{FiO}_{2}$ or $\mathrm{SpO}_{2} / \mathrm{FiO}_{2}$ in 36 consecutive treated patients has been reached without any observed harmful effects attributable to the treatment.

To date, five investigation groups have published results from the use of LD-RT for patients with SARS-CoV-2 pneumonia. One trial has presented preliminary results for 2 patients and one case report has also been published. Ameri et al. have presented the results of an Iranian study (NCT04390412) on 5 patients who received a single dose of $0.5 \mathrm{~Gy}$ to both lungs. In $4 / 5$ patients, an improvement in clinical parameters (blood oxygenation and body temperature) and inflammatory markers (IL-6 and CRP levels) was observed on the first day after treatment. No patient received any other specific treatment for COVID-19 infection. One patient died after 3 days, 1 patient chose to drop 
out of the study after 3 days, and another 3 patients were discharged. No complications related to LD-RT were reported [23]. Preliminary results of the Emory University Hospital RESCUE 1-19 trial have been published by Hess et al. Five patients diagnosed with COVID-19 pneumonia received a single $1.5 \mathrm{~Gy}$ fraction over both lungs. Four of the 5 patients experienced clinical recovery, 3 of them within the first $24 \mathrm{~h}$ after irradiation and could be discharged after a median admission of 12 days. No patient received treatment with drugs directed against COVID-19 in the days before or after lung LD-RT. The authors report no acute toxicity attributable to treatment [24]. These same authors recently updated their results during the American Society for Radiation Oncology (ASTRO) 2020 Annual Meeting. The results have been presented for 20 patients, 10 of whom received low-dose bilateral pulmonary irradiation while another 10 served as controls. They reported a significant decrease in the median time to clinical recovery in the pulmonary irradiation group ( 3 days vs 12 days, hazard ratio $[\mathrm{HR}] 2.0, p=0.05$ ). Additionally, they reported that LDRT improved delirium, radiographs, and biomarkers, with no significant acute toxicity [25]. Moreno-Olmedo et al. have reported preliminary results of the ULTRA-COVID trial (NCT04394182) in 2 patients who received a single 0.8 Gy dose whole lung irradiation through a Tomotherapy. Both patients experienced clinical improvement after LD-RT according to the increase in $\mathrm{PaO}_{2} / \mathrm{FiO}_{2}$ ratio above $300 \mathrm{~mm} \mathrm{Hg}$ as well as reduced dyspnea, asthenia and bilateral pulmonary infiltrative pattern, visible in the chest CT. In addition, the authors also report a decrease in inflammatory parameters, especially IL-6 levels [26]. Del Castillo et al. have reported satisfactory results after a single $1 \mathrm{~Gy}$ whole lung irradiation for a 64-year-old patient presenting with COVID-19 pneumonia and a rapidly deteriorating respiratory function [27]. Sanmamed et al. (NCT04420390) recently reported on 9 patients with COVID-19 pneumonia who underwent whole lung single $1 \mathrm{~Gy}$ fraction with primary endpoint of radiological response. The authors reported a significant improvement in the extension of CT pneumonia as well as in $\mathrm{SpO}_{2} / \mathrm{FIO}_{2}$ at $72 \mathrm{~h}$ and 1 week after LD-RT [28]. Finally, Papachristofilou et al. have published the results of the first randomized trial of whole lung LD-RT for the treatment of COVID19 pneumonia (NCT04598581). The authors analyze the results observed in 22 patients randomized to receive a single whole lung dose (1 Gy) or not. Only elderly patients admitted to the ICU who would require intubation and mechanical ventilation were selected. Beyond the technique used for LD-RT, also debatable because it is far from the quality standards required by modern radiotherapy, the results of the study did not demonstrate the benefit of LD-RT in improving the situation of critically ill patients in the ICU, therefore advising against its use. However, as the authors themselves acknowledge, one of the reasons that could justify the lack of benefit lies in the selection of patients, with an extremely critical condition requiring constant mechanical ventilation [29]. Probably, like it has been previously commented, LD-RT should be considered in the initial phases of the exacerbated inflammatory response that accompanies the SARS-CoV-2 infection, the so-called 'cytokine storm', in order to maximize the antiinflammatory effect of dexamethasone.

One of the main barriers when considering the use of LD-RT for the symptomatic treatment of pneumonia in the context of COVID-19 is the safety of the treatment and the prevention of possible toxicity secondary to radiation therapy. However, none of the previously cited studies have reported complications secondary to radiotherapy. Radiation doses for COVID-19 pneumonia are very low $(<1 \%$ of the doses used for cancer radiotherapy), not exceeding tolerance doses for critical organs (heart, thyroid, stomach or kidneys) nor increasing the risk of development of secondary cancers, which also remains extremely low [30-32]. Preclinical studies showed that doses higher than $200 \mathrm{cGy}$ induce a pro-inflammatory effect directly related to late complications with radiotherapy. However, doses below 100 cGy were associated with an anti-inflammatory effect [9]. Thereby, studies with FDG-PET have shown an increased risk of pulmonary toxicity in patients who receive a mean dose to the lung above $2-5 \mathrm{~Gy}$, far from the doses administered for the treatment of COVID-19 pneumonia, as is the case with the hypothetical risk of cardiac toxicity [10]. In a recent study based on a virtual case simulation, a radiation dose $\leq 0.5$ Gy provided an acceptable lifetime attributable risks (LAR) estimate $(\leq 1 \%)$ for radiation-induced cancer (RIC) and cardiovascular risk of exposure-induced death (REID), regardless of sex and age [33]. Nevertheless, the risk must always be taken into consideration. The consequences of not receiving a treatment that is proving its effectiveness should also be evaluated, even more when the target of patients includes those with advanced age and worse clinical situation not candidates for extreme measures, for which the benefit-risk balance certainly appears favorable. The safety of treatments for COVID-19 pneumonia has also been presented in various studies as well as adverse effects has also been associated to other treatments used for the symptomatic relief of patients with COVID19 pneumonia. Thus, the use of remdesivir has been linked to an appearance of rash, diarrhea, constipation, impaired liver and kidney function and, particularly, cardiotoxicity, which can occasionally be severe $[34,35]$. Similarly, the humanized recombinant monoclonal antibody tocilizumab, directed against the IL- 6 receptor, has also been linked to the appearance of complications, sometimes severe, including infections, neutropenia, or alterations in liver enzymes [36]. 
Our results are in agreement with those reported by other groups. To our knowledge, the present series is the longest of all the experiences published to date and, although it is a nonrandomized trial and the follow-up is still short, observed results suggest a benefit of pulmonary LD-RT for the relief of COVID-19 pneumonia in selected patients. Of the 36 patients initially included in this trial, 8 of them died of COVID-19 disease and 5 of other causes. For 21 of the 25 evaluable patients $(84 \%)$, the rate of improvement in $\mathrm{SpO}_{2} / \mathrm{FIO}_{2}$ reached $76 \%$ after 1 week and respiratory parameters noticeably improved together with a marked reduction in serum inflammation parameters. In those who survived, the CT scan at 1 week after LD-RT showed a significant improvement in the percentage of lung involvement.

Pulmonary LD-RT is an alternative that is worth exploring in the current context of the COVID-19 pandemic and LD-RT should be considered before the inflammatory cascade, which is largely responsible for the symptoms of COVID-19, is completely established. Otherwise, at the moment that the respiratory and clinical condition of patients is at serious risk of fatal deterioration, LD-RT would be unable to reverse it. In addition to the possible efficacy suggested by different studies, other potential advantages of the use of LD-RT in COVID-19 would be that it is not a competitive treatment that would prevent or interfere with the administration of other therapeutic measures, that it is already available in most general hospitals, and that its availability is not subject to stock shortages or market fluctuations.

Not only should the status of COVID-19 pneumonia be an indicator for pulmonary LD-RT, but also should the baseline condition of patients and their cognitive ability to adequately collaborate during and after treatment be taken into account from the beginning. From observed results, we suggest that LD-RT should be considered earlier in the evolution of the disease, in its more initial stages, and for individuals with fewer comorbidities and greater expectations of improvement.

\section{Conclusions}

The use of pulmonary LD-RT, as indicated in this and other ongoing trials, appears to be safe and feasible for patients with COVID-19 pneumonia and deserves to be explored. However, a suitable moment for its use, probably in the earlier stages of the disease, as well as a suitable selection of candidate patients, would be a fundamental requirement if we are to maximize its benefit. Although the present study presented only the results of the first phase of the study including those patients who have received LD-RT, results are encouraging. The analysis of the complete series together with the control group according to the original design of the IPACOVID trial is ongoing and its results are pending publication. Nevertheless, further studies with longer follow-up are necessary to confirm these promising results.

Supplementary Information The online version of this article (https:// doi.org/10.1007/s00066-021-01803-3) contains supplementary material, which is available to authorized users.

Acknowledgements To the Spanish Group for Clinical Research in Radiation Oncology-Spanish Society of Radiation Oncology (GICOR-SEOR 2020) for an extraordinary grant for radiation research during COVID-19 to cover the cost of legal insurance for the clinical trial. To Dr. V. Valentí by his draft review and his insight comments. To all professionals who make the treatment of patients possible: radiotherapy technicians, nurses, physicists, paramedics, cleaning staff, and all the doctors.

Funding Open Access funding provided thanks to the CRUE-CSIC agreement with Springer Nature.

Conflict of interest M. Arenas, M. Algara, G. De Febrer, C. Rubio, X. Sanz, M.A. de la Casa, C. Vasco, J. Marín, P. Fernández-Letón, J. Villar, L. Torres-Royo, P. Villares, I. Membrive, J. Acosta, M. LópezCano, P. Araguas, J. Quera, F. Rodríguez-Tomás and A. Montero declare that they have no competing interests.

Open Access This article is licensed under a Creative Commons Attribution 4.0 International License, which permits use, sharing, adaptation, distribution and reproduction in any medium or format, as long as you give appropriate credit to the original author(s) and the source, provide a link to the Creative Commons licence, and indicate if changes were made. The images or other third party material in this article are included in the article's Creative Commons licence, unless indicated otherwise in a credit line to the material. If material is not included in the article's Creative Commons licence and your intended use is not permitted by statutory regulation or exceeds the permitted use, you will need to obtain permission directly from the copyright holder. To view a copy of this licence, visit http://creativecommons.org/licenses/by/4. $0 \%$

\section{References}

1. Mehta P, McAuley DF, Brown M, Sanchez E, Tattersall RS, Manson JJ, HLH Across Speciality Collaboration, UK (2020) COVID19: consider cytokine storm syndromes and immunosuppression. Lancet 395(10229):1033-1034. https://doi.org/10.1016/S01406736(20)30628-0

2. Calabrese EJ, Dhawan G, Kapoor R (2017) Radiotherapy for pertussis: an historical assessment. Dose Response. https://doi.org/10. $1177 / 1559325817704760$

3. Calabrese EJ, Dhawan G, Kapoor R (2015) The use of X rays in the treatment of bronchial asthma: a historical assessment. Radiat Res 184(2):180-192. https://doi.org/10.1667/rr14080.1

4. Calabrese EJ, Dhawan G (2013) How radiotherapy was historically used to treat pneumonia: could it be useful today? Yale J Biol Med 86(4):555-570

5. Arenas M, Sabater S, Hernández V et al (2012) Anti-inflammatory effects of low-dose radiotherapy. Indications, dose, and radiobiological mechanisms involved. Strahlenther Onkol 188(11):975-981. https://doi.org/10.1007/s00066-012-0170-8

6. Rödel F, Frey B, Manda K et al (2012) Immunomodulatory properties and molecular effects in inflammatory diseases of low- 
dose $\mathrm{x}$-irradiation. Front Oncol 2:120. https://doi.org/10.3389/fonc. 2012.00120

7. Lödermann B, Wunderlich R, Frey S et al (2012) Low dose ionising radiation leads to a NF- $\kappa \mathrm{B}$ dependent decreased secretion of active IL- $1 \beta$ by activated macrophages with a discontinuous dosedependency. Int J Radiat Biol 88(10):727-734

8. Torres Royo L, Antelo Redondo G, ÁrquezPianetta M, Arenas Prat M (2020) Low-Dose radiation therapy for benign pathologies. Rep Pract Oncol Radiother 25(2):250-254. https://doi.org/10.1016/ j.rpor.2020.02.004

9. Arenas M, Gil F, Gironella M et al (2008) Time course of anti-inflammatory effect of low-dose radiotherapy: correlation with TGFbeta(1) expression. Radiother Oncol 86(3):399-406. https://doi.org/ 10.1016/j.radonc.2007.10.032

10. Pandey BN (2020) Low-dose radiation therapy for coronavirus disease-2019 pneumonia: is it time to look beyond apprehensions? Ann Thorac Med 15:199-207

11. Algara M, Arenas M, Marin J et al (2020) Low dose anti-inflammatory radiotherapy for the treatment of pneumonia by covid-19: a proposal for a multi-centric prospective trial. Clin Transl Radiat Oncol 24:29-33. https://doi.org/10.1016/j.ctro.2020.06.005

12. Jamilloux Y, Henry T, Belot A et al (2020) Should we stimulate or suppress immune responses in COVID-19? Cytokine and anticytokine interventions. Autoimmun Rev 19(7):102567. https://doi. org/10.1016/j.autrev.2020.102567

13. Siemieniuk RA, Bartoszko JJ, Ge L et al (2020) Drug treatments for covid-19: living systematic review and network meta-analysis. BMJ 370:m2980. https://doi.org/10.1136/bmj.m2980

14. Conti P, Ronconi G, Caraffa A et al (2020) Induction of pro-inflammatory cytokines (IL-1 and IL-6) and lung inflammation by Coronavirus-19 (COVI-19 or SARS-CoV-2): anti-inflammatory strategies. J Biol Regul Homeost Agents 34(2):327-331. https://doi.org/ 10.23812/CONTI-E

15. Siddiqi HK, Mehra MR (2020) COVID-19 illness in native and immunosuppressed states: a clinical-therapeutic staging proposal. J Heart Lung Transplant. https://doi.org/10.1016/j.healun.2020.03. 012

16. RECOVERY Collaborative Group, Horby P, Lim WS, Emberson JR et al (2020) Dexamethasone in hospitalized patients with Covid-19-preliminary report. N Engl J Med. https://doi.org/10. 1056/NEJMoa2021436

17. Beigel JH, Tomashek KM, Dodd LE, ACTT-1 Study Group Members et al (2020) Remdesivir for the treatment of Covid-19-final report. N Engl J Med. https://doi.org/10.1056/NEJMoa2007764

18. Juul S, Nielsen EE, Feinberg J et al (2020) Interventions for treatment of COVID-19: a living systematic review with meta-analyses and trial sequential analyses (the LIVING project). PLoS Med 17(9):e1003293. https://doi.org/10.1371/journal.pmed.1003293

19. Sun M, Xu Y, He H et al (2020) A potentially effective treatment for COVID-19: A systematic review and meta-analysis of convalescent plasma therapy in treating severe infectious disease. Int J Infect Dis 98:334-346. https://doi.org/10.1016/j.ijid.2020.06.107

20. Dhawan G, Kapoor R, Dhawan R et al (2020) Low dose radiation therapy as a potential life saving treatment for COVID-19-induced acute respiratory distress syndrome (ARDS). Radiother Oncol 147:212-216. https://doi.org/10.1016/j.radonc.2020.05.002

21. Lara PC, Burgos J, Macias D (2020) Low dose lung radiotherapy for COVID-19 pneumonia. The rationale for a cost-effective anti-inflammatory treatment. Clin Transl Radiat Oncol 23:27-29. https://doi.org/10.1016/j.ctro.2020.04.006

22. Prasanna PG, Woloschak GE, DiCarlo AL et al (2020) Low-dose radiation therapy (LDRT) for COVID-19: benefits or risks? Radiat Res 194(5):452-464. https://doi.org/10.1667/RADE-20-00211.1
23. Ameri A, Rahnama N, Bozorgmehr R et al (2020) Low-dose wholelung irradiation for COVID-19 pneumonia: short course results. Int J Radiat Oncol Biol Phys 108(5):1134-1139. https://doi.org/10. 1016/j.ijrobp.2020.07.026

24. Hess CB, Buchwald ZS, Stokes W et al (2020) Low-dose wholelung radiation for COVID-19 pneumonia: planned day 7 interim analysis of a registered clinical trial. Cancer 126:5109-5113. https://doi.org/10.1002/cncr.33130

25. Hess CB, Nasti TH, Dhere V et al (2021) Immunomodulatory low-dose whole-lung radiation for patients with COVID-19-related pneumonia. Int J Radiat Oncol Biol Phys. https://doi.org/10.1016/j. ijrobp.2020.12.011

26. Moreno-Olmedo E, Suárez-Gironzini V, Pérez M, Filigheddu T, Mínguez C, Sanjuan-Sanjuan A, González JA, Rivas D, Gorospe L, Larrea L, López E (2021) COVID-19 pneumonia treated with ultra-low doses of radiotherapy (ULTRA-COVID study): a single institution report of two cases. Strahlenther Onkol 197(5):429-437. https://doi.org/10.1007/s00066-020-01743-4

27. Del Castillo R, Martinez D, Sarria GJ et al (2020) Low-dose radiotherapy for COVID-19 pneumonia treatment: case report, procedure, and literature review. Strahlenther Onkol 196(12):1086-1093. https://doi.org/10.1007/s00066-020-01675-z

28. Sanmamed N, Alcantara P, Cerezo E et al (2020) Low dose radiotherapy in the management of covid19 pneumonia (LOWRADCov19). Preliminary report. Int J Radiat Oncol Biol Phys. https:// doi.org/10.1016/j.ijrobp.2020.11.049

29. Papachristofilou A, Finazzi T, Blum A, Zehnder T, Zellweger N, Lustenberger J, Bauer T, Dott C, Avcu Y, Kohler G, Zimmermann F, Pargger H, Siegemund M (2021) Low-dose radiation therapy for severe COVID-19 pneumonia: a randomized double-blind study. Int J Radiat Oncol Biol Phys. https://doi.org/10.1016/j.ijrobp.2021.02. 054

30. Jansen JT, Broerse JJ, Zoetelief J, Klein C, Seegenschmiedt HM (2005) Estimation of the carcinogenic risk of radiotherapy of benign diseases from shoulder to heel. Radiother Oncol 76(3):270-277. https://doi.org/10.1016/j.radonc.2005.06.034

31. Mazonakis M, Damilakis J (2017) Cancer risk after radiotherapy for benign diseases. Phys Med 42:285-291

32. McKeown SR, Hatfield P, Prestwich RJ, Shaffer RE, Taylor RE (2015) Radiotherapy for benign disease; assessing the risk of radiation-induced cancer following exposure to intermediate dose radiation. Br J Radiol 88(1056):20150405. https://doi.org/10.1259/bjr. 20150405

33. Arruda GV, Weber RRDS, Bruno AC, Pavoni JF (2021) The risk of induced cancer and ischemic heart disease following low dose lung irradiation for COVID-19: estimation based on a virtual case. Int J Radiat Biol 97(2):120-125. https://doi.org/10.1080/09553002. 2021

34. Fan Q, Zhang B, Ma J, Zhang S (2020) Safety profile of the antiviral drug remdesivir: an update. Biomed Pharmacother 130:110532. https://doi.org/10.1016/j.biopha.2020.110532

35. Choi SW, Shin JS, Park SJ et al (2020) Antiviral activity and safety of remdesivir against SARS-CoV-2 infection in human pluripotent stem cell-derived cardiomyocytes. Antiviral Res. https://doi.org/10. 1016/j.antiviral.2020.104955

36. Khiali S, Khani E, Entezari-Maleki T (2020) A comprehensive review of tocilizumab in COVID-19 acute respiratory distress syndrome. J Clin Pharmacol 60(9):1131-1146. https://doi.org/10.1002/ jcph. 1693 


\section{Affiliations}

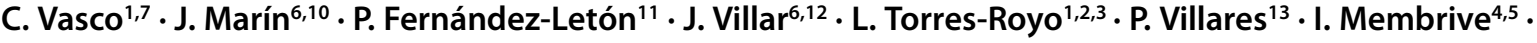

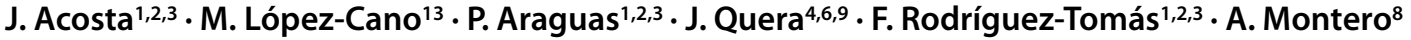

\author{
M. Arenas, $\mathrm{MD}, \mathrm{PhD}$ \\ marenas@grupsagessa.cat \\ G. De Febrer, MD, PhD \\ gdefebrer@grupsagessa.com \\ C. Rubio, $\mathrm{MD}, \mathrm{PhD}$ \\ crubio@hmhospitales.com
}

X. Sanz, MD, PhD

jsanz@psmar.cat

M. A. de la Casa, MD

mdelacasa@hmhospitales.com

C. Vasco, MD

carlosarturo.vasco@grupsagessa.com

J. Marín, MD, PHD

jmarincorral@psmar.cat

P. Fernández-Letón, MD

pfernandezleton@hmhospitales.com

J. Villar, $\mathrm{MD}, \mathrm{PhD}$

JVillar@parcdesalutmar.cat

L. Torres-Royo, MD

laura.torres@grupsagessa.com

P. Villares, MD, PhD

pvillares@hmhospitales.com

I. Membrive

imembrive@psmar.cat

J. Acosta

Johana.acosta@grupsagessa.com

P. Araguas, MD

pablo.araguas@grupsagessa.com
J. Quera, MD

jquera@psmar.cat

F. Rodríguez-Tomás, MD

elisabet.rodriguez@urv.cat

A. Montero, $\mathrm{MD}, \mathrm{PhD}$

angel.monteroluis@gmail.com

1 Universitat Rovira i Virgili, Tarragona, Spain

2 Institut d'Investigacions Pere Virgili, Tarragona, Spain

3 Department of Radiation Oncology, Hospital Universitari Sant Joan de Reus, Tarragona, Spain

4 Department of Radiation Oncology, Hospital del Mar, Barcelona, Spain

5 Autonomous University of Barcelona, Barcelona, Spain

6 Institut Hospital del Mar d'Investigacions Mèdiques, Barcelona, Spain

7 Department of Geriatric and Palliative care, Hospital Universitari Sant Joan de Reus, Tarragona, Spain

8 Department of Radiation Oncology, HM Hospitales., Madrid, Spain

9 Pompeu Fabra University Barcelona, Barcelona, Spain

10 Department of Critical Care, Hospital del Mar, Barcelona, Spain

11 Department of Medical Physics, HM Hospitales, Madrid, Spain

12 Department of Infection Diseases, Hospital del Mar, Barcelona, Spain

13 Department of Internal Medicine, HM Hospitales, Madrid, Spain 